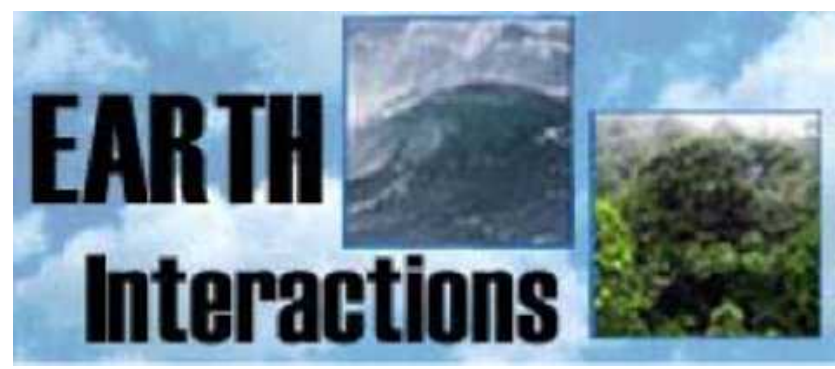

Copyright $\odot$ 2005, Paper 09-008; 8,957 words, 5 Figures, 0 Animations, 7 Tables. http://EarthInteractions.org

\title{
Rapid Assessment of Annual Deforestation in the Brazilian Amazon Using MODIS Data
}

\section{Douglas C. Morton* and Ruth S. DeFries}

University of Maryland, College Park, College Park, Maryland

\section{Yosio E. Shimabukuro, Liana O. Anderson, and Fernando Del Bon Espírito-Santo}

Instituto Nacional de Pesquisas Espaciais, São José dos Campos, São Paulo, Brazil

\section{Matthew Hansen}

South Dakota State University, Brookings, South Dakota

\section{Mark Carroll}

University of Maryland, College Park, College Park, Maryland

Received 15 September 2004; in final form 2 February 2005

ABSTRACT: The Brazilian government annually assesses the extent of deforestation in the Legal Amazon for a variety of scientific and policy applications. Currently, the assessment requires the processing and storing of large volumes of Landsat satellite data. The potential for efficient, accurate, and less

* Corresponding author address: Douglas C. Morton, University of Maryland, College Park, College Park, MD 20742

E-mail address: morton@geog.umd.edu 
Earth Interactions - Volume 9 (2005) - Paper No. 8 - Page 2

data-intensive assessment of annual deforestation using data from NASA's Moderate Resolution Imaging Spectroradiometer (MODIS) at 250-m resolution is evaluated. Landsat-derived deforestation estimates are compared to MODIS-derived estimates for six Landsat scenes with five change-detection algorithms and a variety of input data-Surface Reflectance (MOD09), Vegetation Indices (MOD13), fraction images derived from a linear mixing model, Vegetation Cover Conversion (MOD44A), and percent tree cover from the Vegetation Continuous Fields (MOD44B) product. Several algorithms generated consistently low commission errors (positive predictive value near 90\%) and identified more than $80 \%$ of deforestation polygons larger than 3 ha. All methods accurately identified polygons larger than 20 ha. However, no method consistently detected a high percent of Landsat-derived deforestation area across all six scenes. Field validation in central Mato Grosso confirmed that all MODIS-derived deforestation clusters larger than three 250-m pixels were true deforestation. Application of this field-validated method to the state of Mato Grosso for 2001-04 highlighted a change in deforestation dynamics; the number of large clusters (>10 MODIS pixels) that were detected doubled, from 750 between August 2001 and August 2002 to over 1500 between August 2003 and August 2004. These analyses demonstrate that MODIS data are appropriate for rapid identification of the location of deforestation areas and trends in deforestation dynamics with greatly reduced storage and processing requirements compared to Landsat-derived assessments. However, the MODIS-based analyses evaluated in this study are not a replacement for high-resolution analyses that estimate the total area of deforestation and identify small clearings.

KEYWORDS: Deforestation; Amazon; MODIS; Remote sensing; Brazil

\section{Introduction}

Deforestation in the humid Tropics is a conspicuous change in land use with myriad impacts on global carbon (e.g., Houghton et al. 2000) and climate (e.g., Salati and Nobre 1991; Werth and Avissar 2002). Deforestation rates in tropical Africa, Southeast Asia, and South America have remained constant or increased over the past two decades (DeFries et al. 2002), elevating the need for frequent and accurate assessment of forest loss. In Brazil, the continued expansion of cattle ranching and mechanized agriculture are important drivers of consistently high rates of forest clearing in the Legal Amazon (Laurence et al. 2004).

Annual estimates of deforestation in the Brazilian Amazon, derived from highresolution satellite data, require the processing and storing of large quantities of data. The Instituto Nacional de Pesquisas Espaciais (INPE) analyzes more than 220 Landsat Thematic Mapper (TM) scenes each year to provide annual highresolution mapping of deforestation as part of the Estimativa do Desflorestamento da Amazônia (PRODES; or Program for the Estimation of Deforestation in the Brazilian Amazon). Recent changes in PRODES methodology have reduced the time that is necessary to analyze this high volume of satellite data (e.g., Shimabukuro et al. 1999), but basinwide estimates still require many months time and thousands of person hours to complete (information available online at http:// www.obt.inpe.br/prodesdigital/metodologia.html). Other tropical deforestation es- 
timates with Landsat or similar high-resolution data have been conducted annually for smaller regions (e.g., Sader et al. 2001; Roberts et al. 2002) or supra-annually for large regions because of high data costs and the processing effort (e.g., Skole and Tucker 1993). Analyses of high-resolution data, such as Landsat for tropical forest regions, also suffer from persistent cloud cover and infrequent repeat coverage (Asner 2001). Few regional high-resolution data products have been formally validated in the field.

Coarse spatial resolution satellite data $(>1 \mathrm{~km})$ have also been used for regional assessments of deforestation. Data from the National Oceanic and Atmospheric Administration's Advanced Very High Resolution Radiometer (AVHRR) have been used to estimate deforestation in the Brazilian Amazon (e.g., Nelson and Holben 1986; Nelson et al. 1987; Shimabukuro et al. 1994) and central Africa (Malingreau et al. 1995) at 1-km resolution, and decadal forest cover loss globally at $8-\mathrm{km}$ resolution (Hansen and DeFries 2004). Other forest cover mapping efforts with coarse-resolution data have used the Japanese Earth Resources Satellite (JERS-1) synthetic aperture radar (Siqueira et al. 2003) and the System Pour l'Observation de la Terre (SPOT) vegetation instrument (e.g., Stibig et al. 2001). Coarse spatial resolution makes these estimates more difficult to use where smalland medium-sized clearings constitute an important fraction of new clearings or when frequent analyses are needed. Also, sensor characteristics such as variable instrument calibration and poor geolocation render these techniques less useful for the routine monitoring of deforestation. Hess et al. (Hess et al. 2002) present a new method for field validation of JERS-1 land-cover data products using digital videography; few other coarse-resolution data products have been formally field validated.

A new generation of moderate-resolution sensors with more frequent coverage of the Brazilian Amazon presents a new opportunity for frequent and efficient assessment of deforestation. The Moderate Resolution Imaging Spectroradiometer (MODIS) instruments aboard the Terra (morning) and Aqua (afternoon) platforms provide consistent daily coverage of the entire globe at $250-1-\mathrm{km}$ resolution with 36 bands of spectral information (Justice et al. 2002). MODIS instruments acquire images of the Brazilian Amazon up to 4 times per day, with a swath width of approximately $2300 \mathrm{~km}$. Raw data are geometrically and radiometrically corrected, processed into products such as surface reflectance and vegetation indices, and distributed at no cost via the Land Processes Distributed Active Archive Center (Justice et al. 2002).

MODIS land-cover products provide several types of input data for monitoring deforestation. Daily and 8-day composite Surface Reflectance (MOD09) and 16day composite Surface Reflectance and Vegetation Indices (MOD13) products are distributed in near-real time, facilitating more frequent analyses of deforestation. Quarterly or annual products, such as Vegetation Cover Conversion (VCC; MOD44A) and Vegetation Continuous Fields (VCF: MOD44B) products, provide periodic estimates of deforestation and forest cover, respectively. Fixed analysis periods for VCC and VCF global products provide routine estimates of deforestation, although infrequent product production may limit the ability to discern temporal information regarding forest clearing. In addition, algorithms that are optimized for global products often do not capture regionally specific variations in the timing and nature of forest clearing. Two additional features of the standard 
MODIS data products facilitate rapid analysis of forest cover. First, MODIS landcover products include a quality assurance (QA) layer that evaluates the quality of input data for each pixel and specifically flags clouds, water, high aerosols, and missing data (Huete et al. 1999). Second, daily imagery and data products are composited at 8-, 16-, and 32-day intervals to minimize the impacts of persistent cloud cover and aerosols.

Several recent studies have explored the possibility of mapping land cover and land-cover change in the Brazilian Amazon with MODIS data. Decision-tree classification of 250-m MODIS data in Pará produced accurate classes of forest and nonforest in comparison to Landsat TM training data (Wessels et al. 2004). Principal sources of classification error were a result of haze or thin clouds and mixed pixels at class boundaries (Wessels et al. 2004). Braswell et al. (Braswell et al. 2003) also found that both the moderate-resolution MODIS and Multiangle Imaging Spectroradiometer (MISR) were able to accurately separate forest and nonforest classes, and, at 1.1-m resolution, subpixel classification using spectral unmixing was important for the proper characterization of nondominant classes such as deforestation. Spectral unmixing of higher-resolution MODIS data (250-500 m) proved useful for classifying land cover (Anderson et al. 2005b) and identifying recent deforestation in daily and composited land-cover products in comparison to Landsat TM classifications (Anderson et al. 2005a). These studies suggest that forest and nonforest discrimination is possible with moderate-resolution data, but accurate classification of forest/nonforest edges requires subpixel classification methods.

There are many potential methods for using MODIS data to monitor deforestation and identify priority locations for examination with high-resolution data. The applicability of different methods depends on many factors, including the required frequency of the result, how easy it is to implement in terms of data handling and computational resources, whether human interpretation is possible or whether the process needs to be completely automated, and accuracy requirements. The most appropriate method also depends on the specific needs for different applications - how important is it to minimize false positives (commission error) compared with false negatives (omission error)? Is total deforestation area required, or is it adequate to identify locations where deforestation has occurred? Is it necessary to detect clearings of all sizes or only large deforestation events?

The goal of this study was to develop, test, and validate simple and efficient methods for the annual or more frequent monitoring of deforestation in the Brazilian Amazon as a basis for prioritizing high-resolution analyses and characterizing recent deforestation dynamics. We compared five change-detection algorithms using input data from four MODIS land-cover products to evaluate annual deforestation detection in the Brazilian Amazon with moderate-resolution data. MODIS classification results were compared to 2002 PRODES deforestation detections to quantify omission and commission and to evaluate the potential for MODIS to identify new clearings of various sizes and total deforestation area. Based on results from six Landsat test scenes, we selected one method for field validation in central Mato Grosso. Finally, we applied the field-validated method to the entire state of Mato Grosso to characterize deforestation dynamics between 2001 and 2004. 


\section{Methods}

\subsection{Study area}

We chose six Landsat scenes from the 2001 and 2002 PRODES analyses to develop and test deforestation detection methods using MODIS data (Figure 1). Test scenes were chosen based on 1) cloud-free Landsat coverage in both 2001 and 2002 PRODES analyses; 2) substantial amounts of new deforestation between 2001 and 2002; 3) regional coverage within the arc of deforestation, representing latitudinal, land-use history, and ecological gradients; and 4) a range of clearing sizes within the scene (Table 1). The forest perimeter-area ratio is also reported for each scene in Table 1 as an estimate of forest fragmentation.

\subsection{Data}

\subsubsection{Landsat-derived deforestation estimates for test scenes}

The PRODES classification separates clouds, nonforest, previous deforestation, new deforestation, and forest classes based on shade, soil, and vegetation endmember proportions from a linear spectral mixing model of Landsat TM data (see

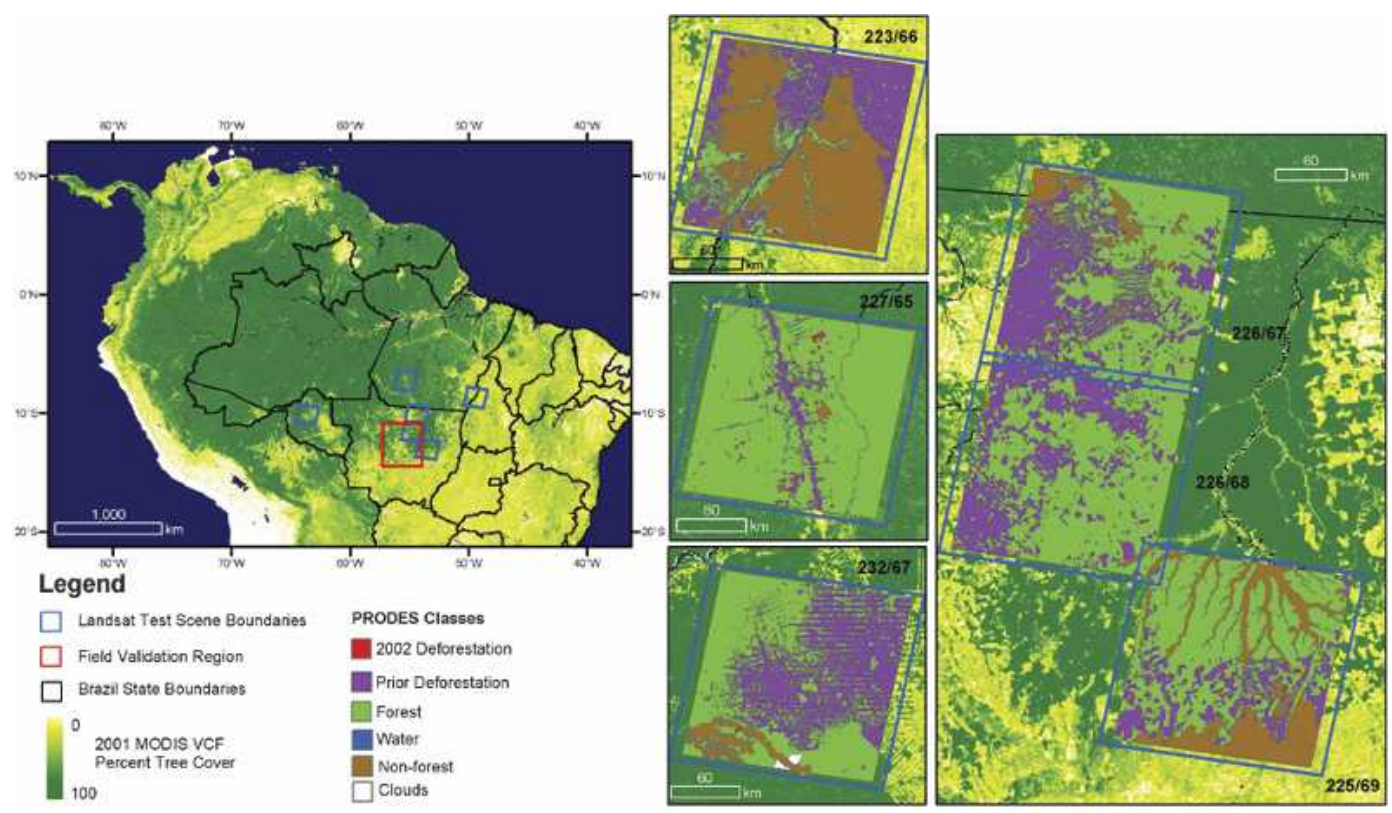

Figure 1. Location of Landsat test scenes and field validation area within the Brazilian Amazon. Percent of tree cover values from the 2001 VCF product show the extent of forest cover in the region. Map subsets show 2002 INPE PRODES classifications for each test scene over 2001 VCF percent of tree cover. Test scenes are presented in counterclockwise order, beginning in the northeast with scene 223/66 and followed by 227/65 in the north, $232 / 67$ in the west, and the cluster of scenes $226 / 67,226 / 68$, and $225 / 69$ in central Mato Grosso. 


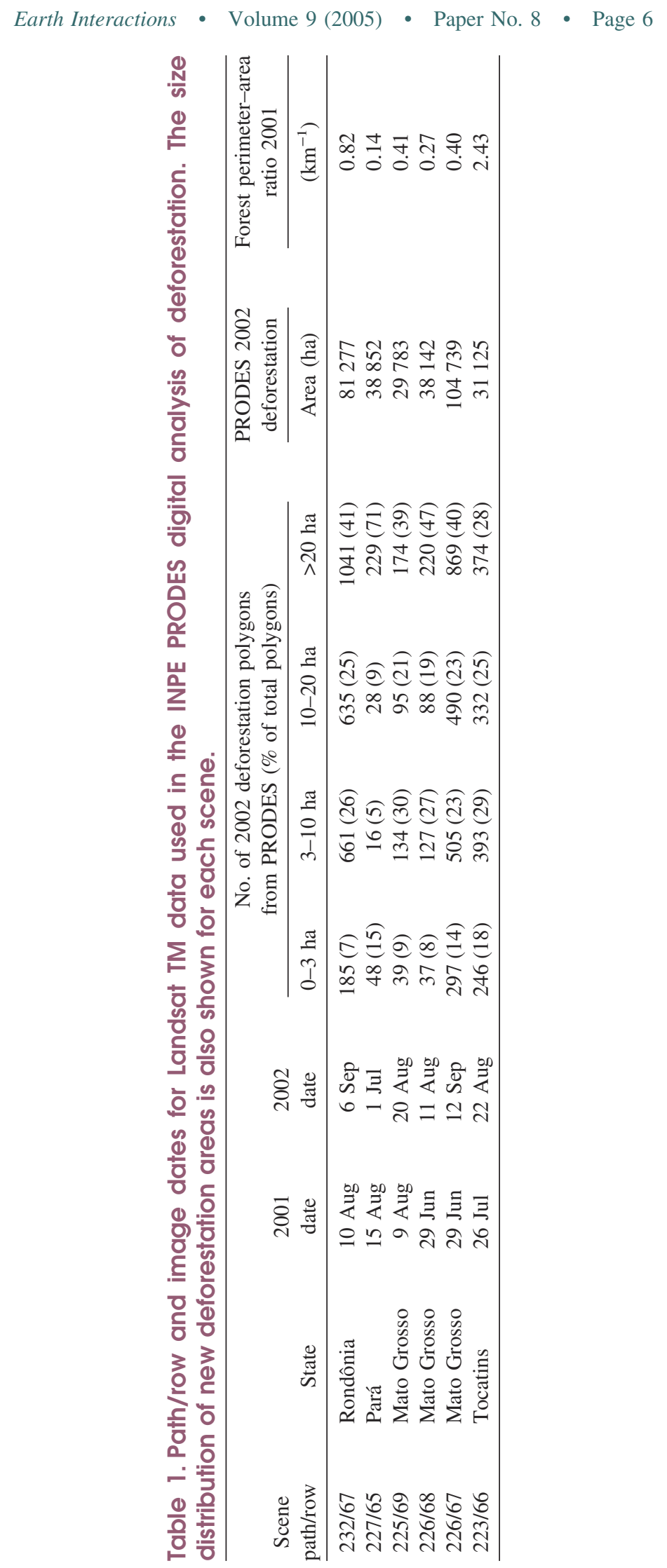


Earth Interactions - Volume 9 (2005) - Paper No. 8 • Page 7

information online at http://www.obt.inpe.br/prodesdigital/metodologia.html). The PRODES methodology involves both automated deforestation detection and confirmation by trained image interpreters (as above, please see online at http:// www.obt.inpe.br/prodesdigital/metodologia.html). In our test scene analysis, forest and deforestation classes from PRODES Digital data were used as "truth" without validation from higher-resolution imagery or field visits. Validation methods are under development, but formal validation statistics are not available for the PRODES data that are used in this study. Areas classified as clouds, nonforest, or previous deforestation in PRODES were excluded from all test scene analyses. Digital PRODES data are distributed at no charge from the INPE Web site (http:// www.obt.inpe.br/prodes/).

\subsubsection{MODIS data preparation}

We compared data from four MODIS land-cover products for deforestation detection. Daily Surface Reflectance (MOD09) and 16-day composite Vegetation Indices (MOD13, includes both surface reflectance and vegetation indices) products are distributed in near-real time. Frequent production and compositing to reduce cloud cover are two advantages of these data products for deforestation monitoring. MOD09 data were acquired for the same dates as the Landsat scenes that are used in PRODES analyses. MOD13 data were chosen for the subsequent 16-day period to avoid omission errors based on compositing rules (Anderson et al. 2005a). We also evaluated preliminary data from the Vegetation Continuous Fields (MOD44B) and Vegetation Cover Conversion (MOD44A) global products. These products are produced on a quarterly or annual basis to assess changes in forest cover. Preliminary MOD44A and MOD44B data products were acquired from MODIS research teams at the University of Maryland, College Park, for 2001 and 2002 by subsetting global products for each test scene (M. Hansen and M. Carroll 2004, personal communication).

Daily MOD09 data were used as algorithm inputs and to derive additional input products. Red and near-infrared (NIR) reflectance bands and the derived normalized difference vegetation index [NDVI; calculated as (Red - NIR)/(Red + NIR)] at 250-m resolution were evaluated in this study. Blue and middle-infrared (MIR) reflectance bands, resampled from 500- to 250-m resolution, were also evaluated for their potential to identify new deforestation. Following the technique proposed by Shimabukuro and Smith (Shimabukuro and Smith 1995), blue, red, NIR, and MIR bands at 250-m resolution were used in a linear spectral mixing model to estimate the subpixel fraction of soil, vegetation, and shade (Anderson et al. 2005a). Nonideal quality data were excluded from analyses based on information contained in the quality control band.

Six data layers from the MOD13 16-day composite product were evaluated in our analysis-NDVI; enhanced vegetation index (EVI); and blue, red, NIR, and MIR reflectances. Nonideal data were identified using the first two bits of the image QA layer and were excluded from the analysis.

Subsets for the test areas were extracted from preliminary MOD44B (VCF) and MOD44A (VCC) global products. VCF percent tree-cover data were resized from 500- to 250-m resolution for this analysis using nearest-neighbor resampling. The VCF algorithm uses metrics from $1 \mathrm{yr}$ (March-February) to assign fractional tree- 
Earth Interactions - Volume 9 (2005) - Paper No. 8 • Page 8

cover values (Hansen et al. 2003). MODIS data from March 2001 to February 2002 were used to create the 2001 VCF product; inputs from March 2002 to February 2003 form the basis of the preliminary 2002 VCF product. The VCC algorithm was run quarterly at 250-m resolution and was summed for the period from July 2001 to September 2002, where persistent drops in tree cover for two or more of the six time periods per quarter were classified as change (Zhan et al. 2002; Carroll et al. 2004).

\subsection{Change detection algorithms}

We evaluated five change detection algorithms to identify new deforestation using a variety of input MODIS datasets (Table 2). All deforestation classifications were restricted to the PRODES-based forest mask area. The five algorithms evaluated in this study were as follows.

1) Two-date image differencing: The difference in the reflectance, vegetation index, or other input data values between images from 2002 and 2001 was classified using mean plus $0.5,1$, or 2 standard deviations of the mean difference. Values that exceeded this threshold were classified as deforestation.

2) Single-date image threshold: The 2001 forest mask pixels were classified using a single 2002 reflectance, vegetation index, or other data layer into forest and deforestation classes based on a threshold derived from decision-tree analysis (Venables and Ripley 1994), using deforestation and forest training data from one scene (Landsat path/row: 226/67). Decisiontree-based thresholds were then applied to all six test scenes. Table 2 lists the data layers that are included in the decision-tree classifier. Data layers were chosen for the test scene analysis based on the low misclassification of training data in the first split of the decision tree.

3) Combined single-date threshold results: A consensus classification method is used where deforestation pixels from two single-date threshold

Table 2. Change detection algorithms and input datasets for test scene method comparison. Results are not shown for input datasets in italics.

\begin{tabular}{|c|c|c|}
\hline Algorithm & $\begin{array}{c}\text { Threshold } \\
\text { determination }\end{array}$ & Input datasets \\
\hline Two-date image difference & $\begin{array}{l}\text { Mean }+ \text { std dev of } \\
\text { mean difference }\end{array}$ & $\begin{array}{l}\text { MOD09: red, NDVI, soil fraction, shade } \\
\text { fraction, vegetation fraction, blue, NIR, } \\
\text { MIR; MOD13: red, NDVI, EVI, blue, NIR, } \\
\text { MIR; MOD44b: percent tree cover }\end{array}$ \\
\hline Single-date image threshold & Decision-tree analysis & $\begin{array}{l}\text { MOD09: NDVI, soil fraction, red, shade } \\
\text { fraction, vegetation fraction, NIR; MOD13 } \\
\text { red, NDVI, NIR; MOD44b: percent of tree } \\
\text { cover }\end{array}$ \\
\hline VCC persistent change & Decision-tree analysis & MOD44a: VCC \\
\hline $\begin{array}{l}\text { Combined single-date threshold } \\
\text { results }\end{array}$ & Decision-tree analysis & $\begin{array}{l}\text { MOD09: red + soil fraction, red + NDVI; } \\
\text { MOD13: red + NDVI }\end{array}$ \\
\hline $\begin{array}{l}\text { NDVI threshold ( } 2002 \text { NDVI < } 0.8) \\
\text { and difference }\end{array}$ & $\begin{array}{l}\text { Mean }+ \text { std dev of } \\
\text { mean difference }\end{array}$ & MOD09: NDVI; MOD13: NDVI \\
\hline
\end{tabular}


Earth Interactions - Volume 9 (2005) - Paper No. 8 - Page 9

results agreed. Combinations were selected from the second split of the decision-tree classifier that best reduced the misclassification of training data.

4) VCC: Decision-tree classification of percent tree cover at 16-day intervals was grouped into five classes of tree cover: 0\%-20\%, 20\%-40\%, 40\%$60 \%, 60 \%-80 \%$, and $80 \%-100 \%$ tree cover. Persistent two-group changes in forest cover [i.e., from group $5(80 \%-100 \%)$ to group $3(40 \%-60 \%)$ ] are summed quarterly into the VCC product (Carroll et al. 2004).

5) NDVI difference with NDVI threshold: This is similar to the two-date image differencing method, but the NDVI difference was only calculated for areas where the 2002 NDVI $<0.8$ to reduce the analysis area and minimize false detections that are a result of seasonal variations in forest phenology. The 2002 NDVI threshold acts as a second forest mask in this method. Values that exceeded the mean difference plus $0.5,1$, or 2 standard deviations of the mean difference were classified as deforestation.

Image differences and single 2002 image thresholds were run separately for MOD09 and MOD13 data to evaluate the difference between daily and composite imagery. A total of 32 input data and change detection algorithm combinations were evaluated for deforestation detection accuracy, but results are only presented for 12 methods. These 12 methods were selected on the basis of performance and to present results for each detection algorithm and input data source.

\subsection{Test scene analysis}

Comparison of results from the change detection algorithms to PRODES Digital deforestation maps was conducted for each input dataset and each of the six test scenes. The comparison was done only for cloud-free pixels by excluding cloudy areas in 2001 or 2002 PRODES classifications and MODIS QA data. Analyses based on MOD09 or MOD13 data were conducted separately using their respective QA layers; VCC and VCF data analyses were conducted using only the PRODES cloud masks, because it was not feasible to assemble QA layers from all of the dates used in the generation of these products. Next, one edge pixel was subtracted from the cloud-free $250-\mathrm{m}$ forest/deforestation dataset to minimize false detections based on variations in MODIS resolution as a result of view angle and product gridding. Finally, forest and deforestation layers were separated to evaluate commission and omission, respectively. The result was a cloud-free comparison of MODIS results with the forest and deforested classes from PRODES, where clouds, forest/nonforest edge pixels, water, previous deforestation, and other nonforest areas were excluded from the analysis. Individual polygons were compared to classification results using zonal statistics, permitting an analysis of deforestation detection by polygon size.

We assessed accuracy for each method and each test scene with respect to PRODES deforestation detections. Commission errors are summarized as a positive predictive value (PPV). PPV is the percent of true positives, calculated as true positive detections/total positive detections. Larger PPV values indicate smaller commission errors. MODIS deforestation detections were also compared to the area of deforestation in PRODES. Finally, the detection of individual deforestation polygons, defined as any MODIS detection within the polygon perimeter, were 
Earth Interactions - Volume 9 (2005) • Paper No. 8 • Page 10

assessed by polygon size to evaluate each method's accuracy in identifying new small, medium, and large clearings. Size classes were based on PRODES polygons-0-3, 3-10, 10-20, and > 20 ha-and detection percentages are reported as the percent of available polygons, noting that many smaller polygons were masked during the removal of clouds and forest edge pixels from the analysis.

\subsection{Field validation}

Based on performance in the test scene analysis (section 2.4.), the single-date threshold method with MOD13 red reflectance was chosen for validation with field observations in central Mato Grosso in July 2004 (Figure 1). Ground-based teams of observers assessed per-pixel and per-cluster accuracy in the following manner.

Using a vector layer of roads in Mato Grosso to stratify the MODIS classification, all forest and deforestation pixels that intersected a road were selected and numbered. Roads, sample pixels, near-coincident Landsat TM and MODIS imagery, and MODIS deforestation classification results were loaded into a geographic information system (GIS) and were compared with real-time GPS coordinates in the field. During the field campaign, 345 forest and 111 deforestation pixels were visited for a total of 456 observations. Pixels with any amount of observed deforestation were classified as deforested. Per-pixel accuracy was established using traditional error matrix techniques (Congalton 1991).

Deforestation clusters were defined as contiguous 250-m MODIS deforestation pixels. To characterize detection accuracy based on cluster size, we observed clusters ranging from single (6.25 ha) to 408 (2550 ha) pixels. For each cluster, GPS points were taken along the roaded edges of the clearing and, when possible, at other points along the perimeter. These measurements and observations were compared with near-coincident Landsat TM images in the field. Clusters that contained new deforestation anywhere within the cluster perimeter were classified as deforested. A total of 120 MODIS deforestation clusters were observed in the field.

\subsection{Mato Grosso deforestation detections 2001-04}

We applied the single-date threshold method using MOD13 red reflectance for the state of Mato Grosso to examine deforestation dynamics between 2001 and 2004. A cloud-free, statewide forest mask was created from 2001 PRODES data. Annual deforestation for 2001-02, 2002-03, and 2003-04 was analyzed using MOD13 red reflectance data from August of each year (composite period: Julian days 209224). The initial forest mask was updated to exclude each year's deforestation increment. Based on results from the field validation study, single-pixel deforestation clusters were removed from classification results.

\section{Results}

\subsection{Method comparison in test scenes}

A variety of techniques accurately identified new deforestation in the six test scenes. Table 3 presents PPV for 10 of 32 individual methods applied to each test 
Earth Interactions - Volume 9 (2005) • Paper No. 8 • Page 11

Table 3. PPV (true positives/total postives) expressed as a percent for each technique across all six test scenes.

\begin{tabular}{lccccccc}
\hline \multicolumn{1}{c}{ Technique } & Threshold & $232 / 67$ & $227 / 65$ & $226 / 68$ & $226 / 67$ & $225 / 69$ & $223 / 66$ \\
\hline MOD09 & & & & & & & \\
Red difference & $\mu+2$ std dev & 56.8 & 68.6 & 83.9 & 82.4 & 77.1 & 90.4 \\
NDVI difference & $\mu+2$ std dev & 59.4 & 69.5 & 88.2 & 78.3 & 82.0 & 91.6 \\
Red + soil fraction & $0.43,20 \%$ & 63.1 & 95.6 & 88.4 & 73.9 & 94.2 & 51.6 \\
Soil fraction & $20 \%$ & 81.1 & 89.4 & 76.9 & 82.1 & 89.8 & 38.5 \\
2002 NDVI & 0.76 & 59.6 & 85.9 & 78.4 & 58.7 & 67.3 & 35.7 \\
MOD13 & & & & & & & \\
Red difference & $\mu+2$ std dev & 64.4 & 67.0 & 87.8 & 77.7 & 76.5 & 89.9 \\
NDVI difference & $\mu+2$ std dev & 72.4 & 73.9 & 93.3 & 78.8 & 78.5 & 90.9 \\
NDVI filtered & $\mu-1 / 2$ std dev & 72.4 & 97.9 & 97.3 & 68.9 & 75.6 & 32.2 \\
2002 red & 0.54 & 74.4 & 100.0 & 98.3 & 84.8 & 92.1 & 84.1 \\
2002 NDVI & 0.76 & 73.0 & 97.4 & 94.0 & 69.5 & 70.0 & 42.8 \\
\hline
\end{tabular}

scene. Variability in the degree of forest fragmentation and distribution of deforestation polygon sizes in each scene impacted detection accuracies (Table 1). In the four scenes with less fragmentation and low forest perimeter-area ratios $(225 / 69,226 / 67,226 / 68$, and 227/65), PPV was consistently high among all of the techniques and was highest for single-date methods. More fragmented forest cover in scenes 223/66 and 232/67 resulted in more false positives in most methods. In these scenes, image-difference methods had higher PPV than single-date approaches. No one method produced the highest PPV across all test scenes.

The percent of PRODES deforestation area that was detected was consistently low for all scenes and was highly variable between scenes for each method (Table $4)$. The percent of actual deforestation area detected was highest for scenes dominated by large clearings. For example, scenes 226/68 and 225/69 showed a higher percent total area detected for high PPV values. More fragmented forest cover in scenes 223/66 and 232/67 created a clearer trade-off between PPV and the percent of total deforestation area detected. No method detected a consistently high percent of total deforestation area across all of the scenes.

Across all six test scenes, polygon detection (any MODIS detection within the

Table 4. Percent of total 2002 PRODES Digital deforestation area detected in each test scene for each technique expressed as a percent.

\begin{tabular}{lccccccc}
\hline \multicolumn{1}{c}{ Technique } & Threshold & $232 / 67$ & $227 / 65$ & $226 / 68$ & $226 / 67$ & $225 / 69$ & $223 / 66$ \\
\hline MOD09 & & & & & & & \\
Red difference & $\mu+2$ std dev & 36.8 & 64.4 & 65.8 & 27.1 & 69.1 & 42.0 \\
NDVI difference & $\mu+2$ std dev & 36.6 & 64.3 & 65.8 & 51.3 & 66.4 & 38.3 \\
Red + soil fraction & $0.43 / 20 \%$ & 32.9 & 28.2 & 64.7 & 61.6 & 51.4 & 79.3 \\
Soil fraction & $20 \%$ & 7.1 & 29.8 & 33.6 & 15.5 & 23.9 & 23.4 \\
2002 NDVI & 0.76 & 39.3 & 44.2 & 73.7 & 77.0 & 73.3 & 83.4 \\
MOD13 & & & & & & & \\
Red difference & $\mu+2$ std dev & 35.8 & 59.9 & 60.8 & 45.7 & 69.3 & 32.4 \\
NDVI difference & $\mu+2$ std dev & 39.0 & 63.2 & 59.6 & 46.1 & 68.1 & 32.4 \\
NDVI filtered & $\mu-1 / 2$ std dev & 39.6 & 31.5 & 52.1 & 57.8 & 71.9 & 81.7 \\
2002 red & 0.54 & 19.5 & 4.7 & 34.4 & 36.0 & 54.3 & 44.2 \\
2002 NDVI & 0.76 & 42.8 & 28.1 & 60.6 & 60.5 & 72.7 & 73.1 \\
\hline
\end{tabular}


deforestation polygon) increased with polygon size (Table 5). Results in Table 5 are reported as a percent of the available polygons, disregarding PRODES deforestation polygons masked out as a result of clouds or the forest edge. Between NDVI methods using MOD09 and MOD13 data, NDVI derived from the daily surface reflectance product gave consistently higher detection for all polygon sizes than from the composited product. For large polygons (>20 ha), all 10 methods in Table 5 produced greater than $75 \%$ detection; three methods detected greater than $90 \%$ of the available polygons in this size class. Polygon detection by size did vary between scenes for each technique (Figure 2). Higher variability in detection estimates for small and medium polygons reflects the lower sample size of available polygons in these size classes.

The number of available polygons was not significantly different between analyses with MOD09 and MOD13 input data (Pearson $\chi^{2}=0.09$, degrees of freedom $(\mathrm{DF})=3, p$ value $=0.99)$. Removing the edge pixel from the forest mask did significantly alter the distribution of available polygons between PRODES Digital and both MOD09 and MOD13 available polygons $\left(\chi^{2}=248.8\right.$, $\mathrm{DF}=3, p$ value $<0.0001)$. Masked polygons that are unavailable for analysis accounted for $8 \%$ of the total deforestation area across all six test scenes (Table 6), compared to the greater than $50 \%$ reduction in commission through edge pixel removal (data not shown). A substantial fraction of small and medium polygons were masked out by removing the edge pixel from the forest mask or through eliminating clouds and other nonideal quality data in MOD09 and MOD13 approaches. The NDVI-filtered method, a two-phase differencing approach, eliminated more polygons from consideration than the other methods because of the use of a second forest mask.

Table 5. Percent of available polygons detected by size class and summarized by technique for all test scenes. Percentages are calculated as detected/available for each technique. The number of polygons detected in each size class is shown in parentheses. Distributions of available polygons in MOD09, MOD13, and NDVI-filtered approaches are significantly different from PRODES Digital polygons $(p<0.0001)$, but are similar between MOD09 and MOD13 $(p=0.99)$.

\begin{tabular}{lccccc}
\hline & $0-3$ ha & $3-10$ ha & $10-20$ ha & $20+$ ha & Tot \\
\hline Total & 636 & 1591 & 1500 & 2784 & 6511 \\
MOD09 & & & & & \\
$\quad$ Available & 170 & 996 & 1152 & 2613 & 4931 \\
$\quad$ Red difference & $13.5(23)$ & $45.7(455)$ & $56.4(650)$ & $83.2(2174)$ & $67.0(3302)$ \\
NDVI difference & $20.6(35)$ & $50.3(501)$ & $60.6(698)$ & $86.3(2254)$ & $70.7(3488)$ \\
Red + soil fraction & $43.5(74)$ & $65.9(656)$ & $78.1(900)$ & $91.4(2387)$ & $81.5(4017)$ \\
Soil fraction & $27.6(47)$ & $42.8(426)$ & $51.0(588)$ & $76.0(1987)$ & $61.8(3048)$ \\
2002 NDVI & $58.8(100)$ & $83.0(827)$ & $90.5(1043)$ & $95.1(2485)$ & $90.3(4455)$ \\
MOD13 & & & & & \\
Available & 171 & 990 & 1149 & 2634 & 4944 \\
Red difference & $19.9(34)$ & $46.2(457)$ & $60.1(691)$ & $85.7(2258)$ & $69.6(3440)$ \\
$\quad$ NDVI difference & $19.9(34)$ & $42.3(419)$ & $56.1(645)$ & $82.2(2164)$ & $66.0(3262)$ \\
2002 red & $17.5(30)$ & $43.1(427)$ & $55.4(636)$ & $77.0(2028)$ & $63.1(3121)$ \\
2002 NDVI & $40.9(70)$ & $71.5(708)$ & $83.6(960)$ & $92.5(2436)$ & $84.4(4174)$ \\
NDVI filtered & & & & & \\
$\quad$ Available & 82 & 560 & 766 & 2318 & 3726 \\
NDVI filtered & $50.0(41)$ & $46.1(258)$ & $55.0(421)$ & $78.9(1828)$ & $68.4(2548)$ \\
\hline
\end{tabular}


Earth Interactions - Volume 9 (2005) - Paper No. 8 - Page 13

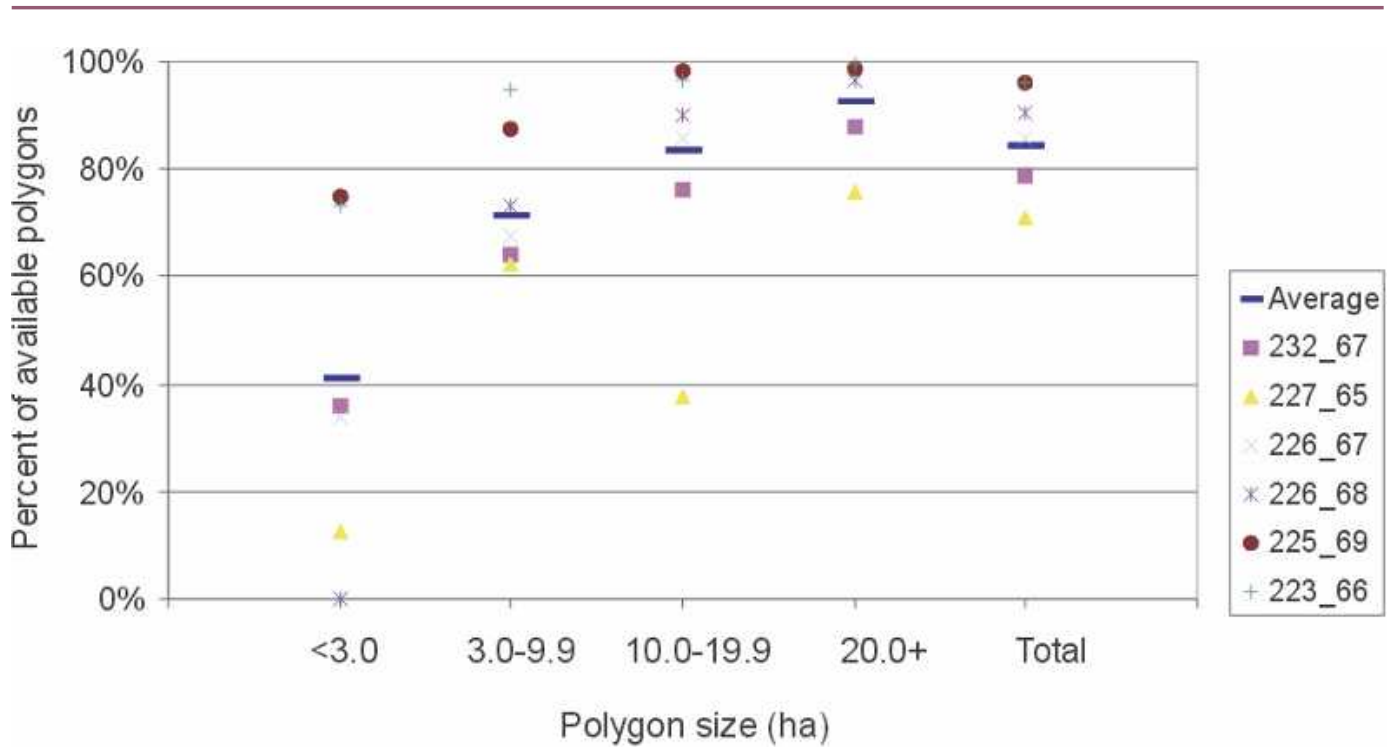

Figure 2. Distribution of the percent of polygons detected by size class for the single-date threshold method using MOD 132002 NDVI. Small sample sizes for available 0-3- and 3-10-ha polygons created wider variations in detection estimates than for polygons $>\mathbf{2 0}$ ha or total polygons, where larger sample sizes show more consistent detection percentages between scenes.

Deforestation detection is summarized by different methods for all six scenes in Table 7. No one method had the highest accuracy with respect to the PPV, area, and polygons detected. Therefore, the most accurate method will depend on the decision to maximize one component. The choice of daily or composited MODIS source data showed little influence on accuracy. For the same methods, MOD09 input data slightly outperformed MOD13 data in the percent of polygons that were detected, performed similarly to MOD13 in the percent of PRODES Digital deforestation area detected, and yet had a lower PPV, on average, than the MOD13 approaches. Methods that used red reflectance and NDVI also showed similar results. NDVI analyses identified greater numbers of small polygons but had higher commission than red reflectance methods. Image difference methods identified a higher percent of deforested area than single-date methods. Soil fraction input data produced results that were consistent with other methods in PPV and

Table 6. Impact of source data and method on deforestation area in available polygons. Areas are reported in hectares by size class. Area in available polgyons as a percent of total PRODES Digital deforestation area is shown in parentheses.

\begin{tabular}{lccccc}
\hline & $0-3$ ha & $3-10$ ha & $10-20$ ha & $20+$ ha & Tot \\
\hline $\begin{array}{l}\text { Total PRODES Digital area } \\
\text { Area in available polygons }\end{array}$ & 808 & 13121 & 23655 & 286334 & 323918 \\
$\quad$ & $176(21.8)$ & $7327(55.8)$ & $16447(9.5)$ & $273428(95.5)$ & $297378(91.8)$ \\
MOD09 & $177(21.9)$ & $7275(55.4)$ & $16412(69.4)$ & $274003(95.7)$ & $297868(92.0)$ \\
MOD13 & $90(11.1)$ & $4107(31.3)$ & $11013(46.6)$ & $261113(91.2)$ & $276323(85.3)$ \\
\hline
\end{tabular}


Earth Interactions • Volume 9 (2005) • Paper No. 8 • Page 14

Table 7. Average percent PPV, percent of PRODES Digital deforestation area detected, and percent of available polygons detected for each technique for all six test scenes.

\begin{tabular}{lcccc}
\hline \multicolumn{1}{c}{ Technique } & Threshold & PPV & $\begin{array}{c}\text { Deforested } \\
\text { area }(\%)\end{array}$ & $\begin{array}{c}\text { Available } \\
\text { polygons }(\%)\end{array}$ \\
\hline MOD09 & & & & \\
Red difference & $\mu+2$ std dev & 76.6 & 50.9 & 67.0 \\
NDVI difference & $\mu+2$ std dev & 78.2 & 53.8 & 70.7 \\
Red + soil fraction & $0.43 / 20 \%$ & 77.8 & 53.0 & 81.5 \\
Soil fraction & $20 \%$ & 76.3 & 22.2 & 61.8 \\
2002 NDVI & 0.76 & 64.3 & 65.1 & 90.3 \\
MOD13 & $\mu+2$ std dev & 77.2 & 50.6 & 69.6 \\
Red difference & $\mu+2$ std dev & 81.3 & 51.4 & 66.0 \\
NDVI difference & $\mu-1 / 2$ std dev & 74.1 & 55.8 & 68.4 \\
NDVI filtered & 0.54 & 89.0 & 32.2 & 63.1 \\
2002 red & 0.76 & 74.4 & 56.3 & 84.4 \\
2002 NDVI & & & & \\
\hline
\end{tabular}

polygons detected. We selected the MOD13 single-date red reflectance method for field validation based on low commission and polygon detection that is comparable with other techniques.

The VCC algorithm had the highest PPV (0.90) for all of the test scenes combined, but the method detected only $20 \%$ of the largest polygons ( $>20$ ha) and less than $10 \%$ of all of the deforestation polygons (data not shown). A deforestation threshold of $<30 \%$ forest cover in $2002 \mathrm{VCF}$ produced results that are consistent with other techniques (PPV =0.72). Differencing VCF 2002 and 2001 products produced modest results $(\mathrm{PPV}=0.57)$, largely a result of compounding the effects of edge pixel errors over 2 yr. Techniques that utilized EVI, MIR, or blue reflectance differences or thresholds had lower PPV results in all of the test scenes (data not shown).

\subsection{Field validation}

Field validation of the 2004 MOD13 red reflectance classification produced measures of per-pixel and per-cluster accuracy. On a per-pixel basis, overall classification accuracy was $81.5 \%$ (393/456 pixels correctly classified). User's and producer's accuracies were $97.6 \%$ (289/296) and 83.7\% (289/345) for forest and 65\% $(104 / 160)$ and $93.7 \%$ (104/111) for deforested classes, respectively. All 56 pixels that were classified as forest and observed as deforestation were at the forest/ deforestation edge, such that the pixels contained a mixture of forest and deforestation. Interobserver accuracy for pixel interpretation in the field was $\pm 5 \%$. Clusters were defined as conterminous groups of MODIS deforested pixelsanalogous to polygons in the PRODES analysis. Of the 120 clusters visited in the field, 109 were observed as deforested (Figure 3). All deforestation clusters larger than two MODIS pixels were observed as actual deforestation in the field.

\subsection{Deforestation detection in Mato Grosso 2001-04}

We applied the field-validated MOD13 red reflectance method to the entire state for the intervals of August 2001-August 2002, August 2002-August 2003, and 


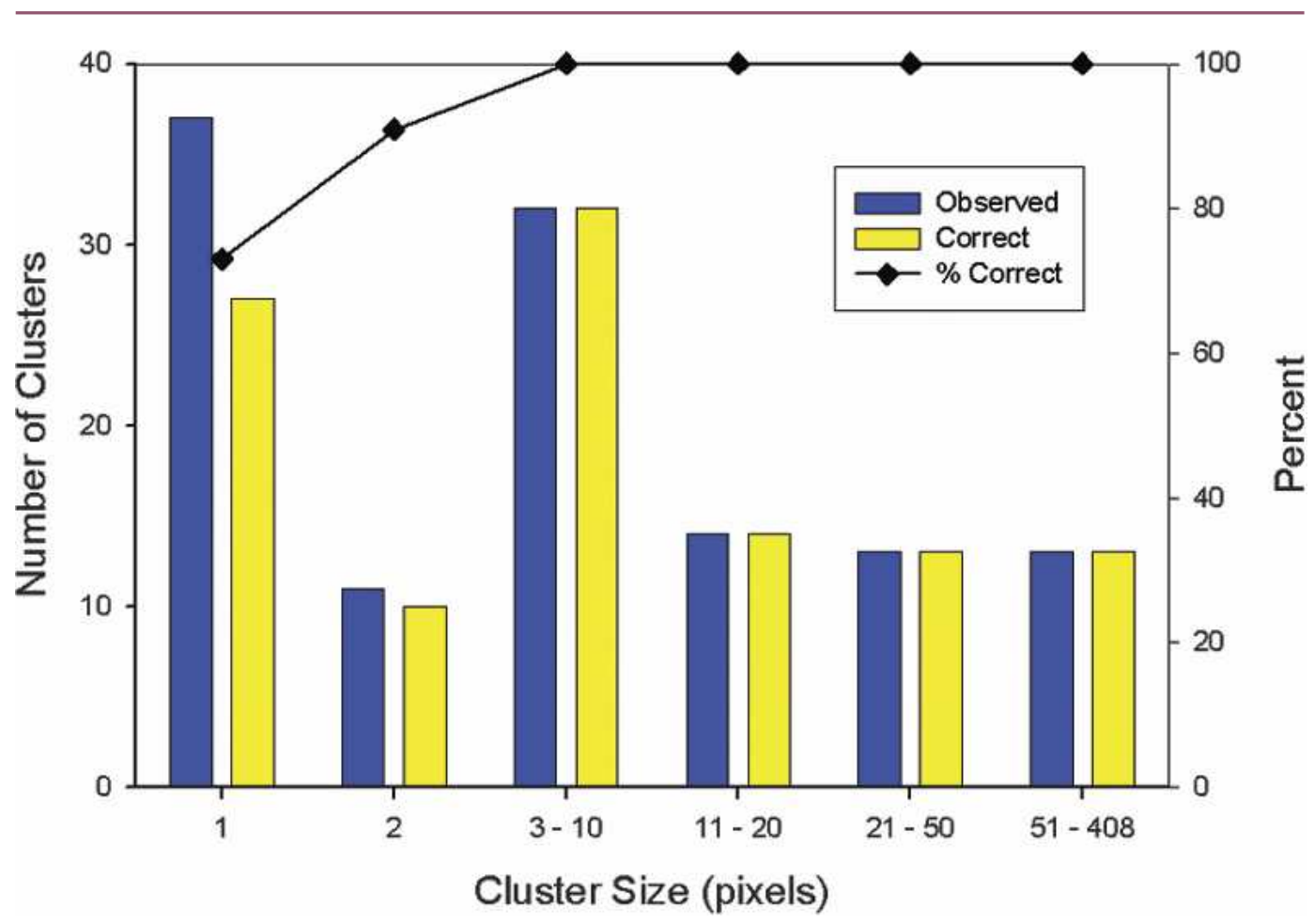

Figure 3. Number of deforestation clusters observed during field validation and the percent correctly classified by cluster size.

August 2003-August 2004 (Figure 4). Single-pixel clusters were removed based on field validation results that indicated lower reliability for single pixels. Figure 5 shows the number of deforestation clusters that are detected each year by cluster size. Between 2001 and 2004, the total number of deforestation clusters detected increased by more than $60 \%$, and the number of large deforestation clusters $(>10$ pixels) doubled.

\section{Discussion}

\subsection{Test scene analysis}

Moderate-resolution satellite data from the MODIS instrument are appropriate for rapid identification of the location of deforestation events and characterization of trends in deforestation dynamics, using simple algorithms and low data volumes. Using a forest/nonforest mask, simple methods, such as image differences and single-date image thresholds, identified greater than $80 \%$ of deforestation polygons in our dataset larger than 3 ha and more than $95 \%$ of polygons 20 ha or larger. Several methods maintained an average PPV above $80 \%$ for all scenes, supporting the idea that the automated processing of MODIS data can be a useful step in monitoring deforestation with few false detections. Individual methods that were developed and field validated in this study identified deforestation events greater 


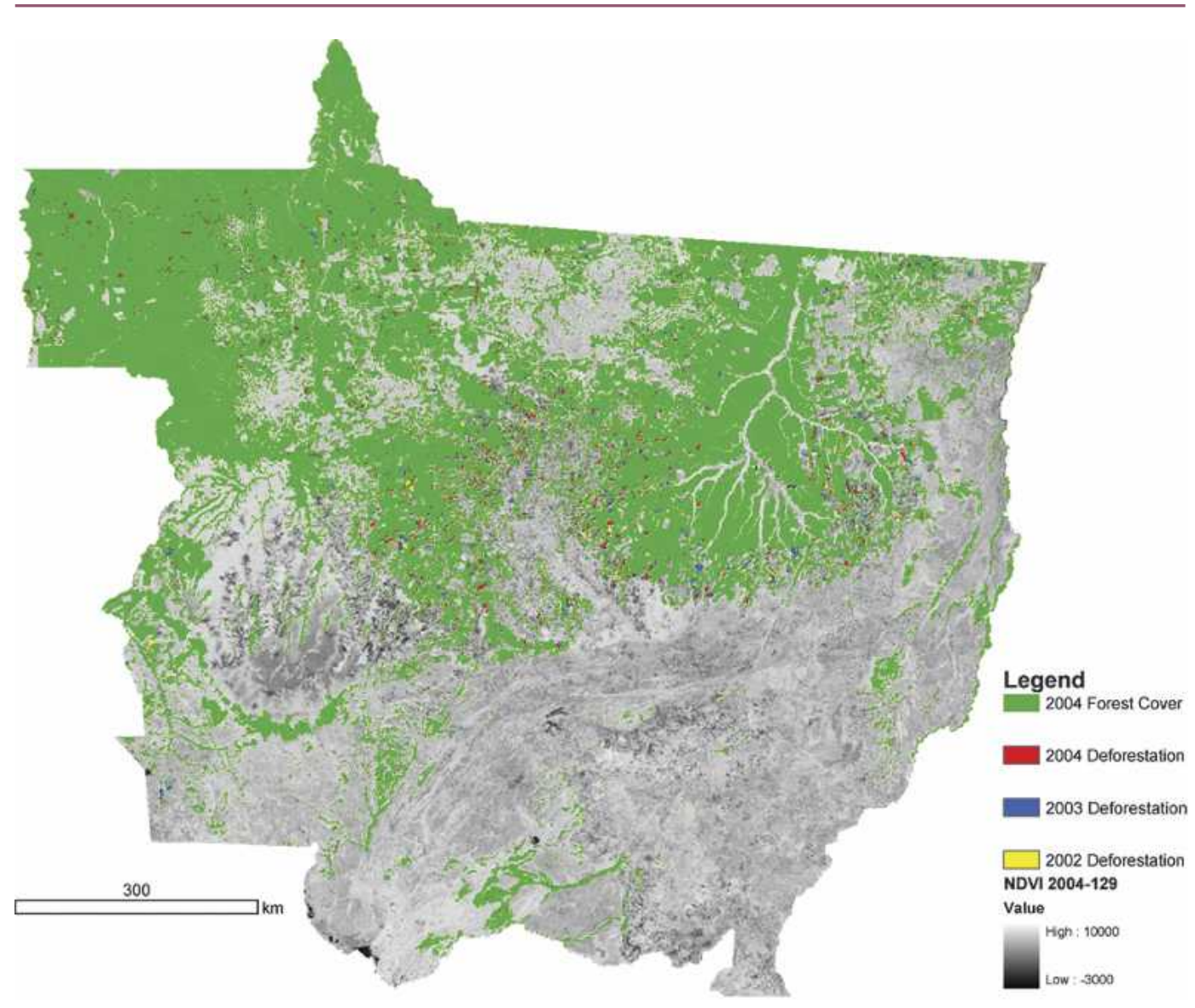

Figure 4. Deforestation detections in Mato Grosso for 2002 (Aug 2001-02; yellow), 2003 (Aug 2002-03; blue), and 2004 (Aug 2003-04; red) are shown. Remaining forest cover in 2004 is shown in green. Background values for nonforested regions are NDVI values from the MOD13 16-day composite from 8 to 23 May 2004 (Julian days 129-144). Single-pixel deforestation clusters were removed based on the lower reliability of single-pixel clusters from field validation results.

than 10 ha with low false detection, suggesting that methods requiring minimal processing and the storage of MODIS data can rapidly identify the location of larger deforestation events.

The MODIS analyses presented in this study are not a replacement for a basinwide analysis of Landsat TM or other high-resolution data. No MODIS algorithm in this study identified a consistently high percentage of the area of new deforestation or the number of small clearings compared to high-resolution data products. Removing an edge pixel from the analysis reduced commission errors, but excluded an important region of analysis for mapping finescale deforestation dynamics. As a result, most small clearings (0-3 ha) at the forest edge were not discernable with MODIS data, especially for two test scenes with highly fragmented forest cover (223/66 and 232/67). Other modifications to the algorithms in this study, such as the independent treatment of pixels at the forest edge or 


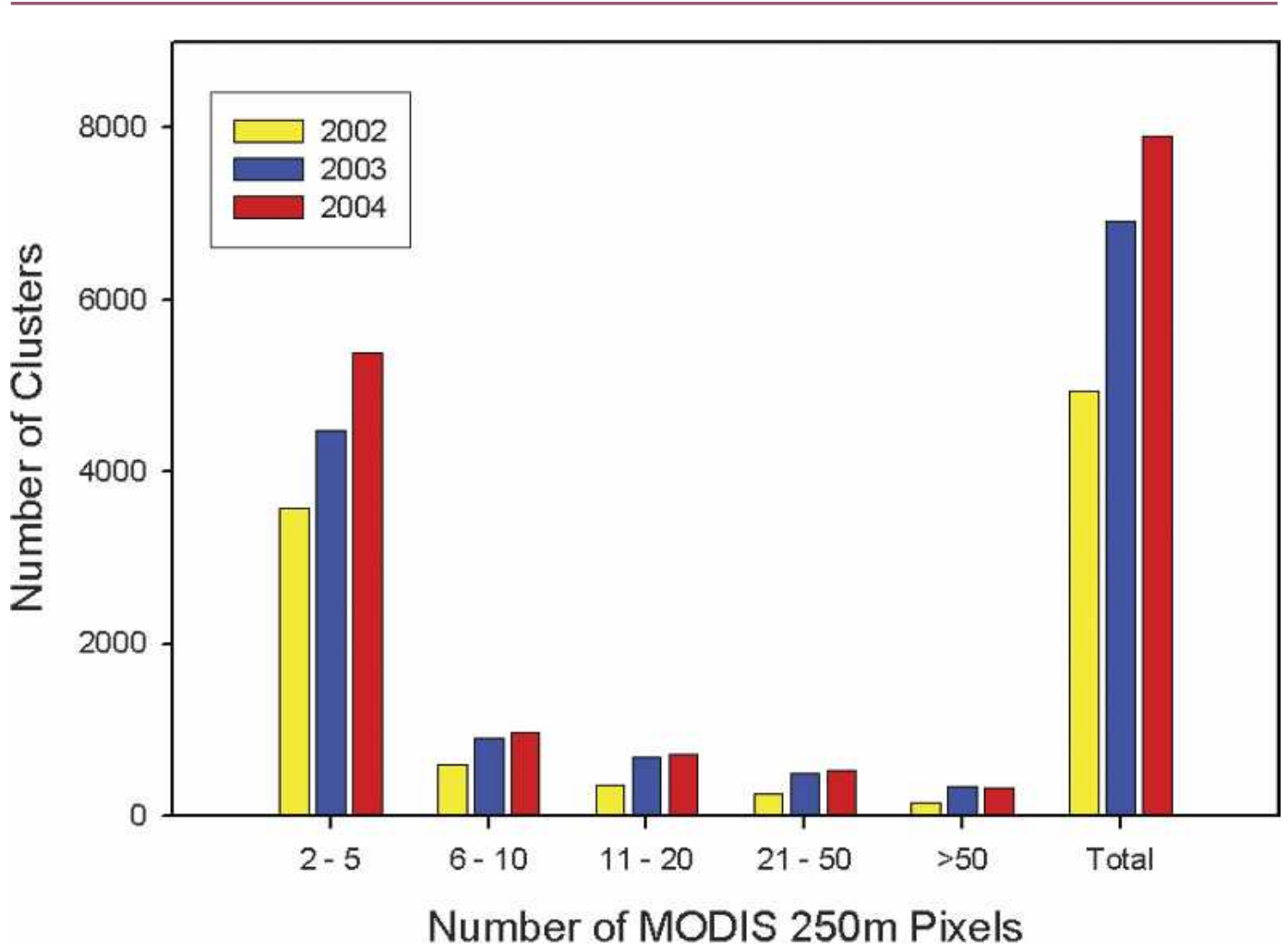

Figure 5. Number of deforestation clusters detected for 2002 (Aug 2001-02), 2003 (Aug 2002-03), and 2004 (Aug 2003-04) in Mato Grosso summarized by cluster size (in MODIS 250-m pixels).

inclusion of only near-nadir pixels, could greatly improve the ability to detect subpixel forest change with 250-m resolution MODIS data. Differences were minimal between the daily and 16-day composite MODIS data that were used as input to change detection algorithms. Images for this study were taken from cloud-free periods near the end of the dry season on an annual basis. Comparative advantages of daily or composited data were minimized by the long analysis interval and cloud-free conditions. At more frequent time steps or during periods of rapid clearing, daily data preserve temporal information regarding forest clearing. Data-compositing algorithms that preferentially select high NDVI values during the compositing period to avoid undetected clouds or smoke, such as the MOD13 algorithm (Huete et al. 1999), may impact deforestation detection by selecting a predeforestation pixel during the compositing period. As a result, evidence of deforestation may not be detected in composited products until the subsequent compositing period, when no predeforestation pixel values exist. During the transition between wet and dry seasons, when both clouds and deforestation are common, quality flags and compositing may prove more essential. However, even "ideal" data based on QA flags contained artifacts from clouds, cloud shadows, or sensor errors, such as striping and missing data. As a result, human interpretation of preprocessed images and classification products may be necessary to ensure high-quality results. Other techniques, such as additional cloud filters or 
water masks in the preprocessing steps, could help to eliminate some of these issues.

The focal region for this study was the arc of deforestation, where a high percentage of the total annual deforestation increment occurs (information available online at http://www.obt.inpe.br/prodes/). Deforestation and climatic characteristics in this region are favorable for MODIS-based deforestation monitoring. Longer dry seasons and lower-stature transition forest types enable the mechanized clearing of forest cover. These larger clearings are more easily detected by the methods presented in this study. Cloud cover is much lower during the dry season (Asner 2001), increasing the chance for cloud-free MODIS imagery. In regions with smaller clearing sizes and more persistent cloud cover, methods that rely on longer compositing periods or higher-resolution data may be more appropriate for deforestation monitoring. In addition, strong seasonal or El Niño-induced phenology, especially in transition forest types along the arc of deforestation, could complicate threshold setting for more frequent monitoring efforts.

Input data from periodic or annual products, such as MOD44A and MOD44B, limit the frequency of deforestation monitoring. The starting and ending dates for annual or periodic data products can also greatly impact the ability to detect deforestation. For example, if deforestation occurs near the end of the processing period, the change may not be detected until the following product cycle. The regional applicability of these data products is constrained by two elements of a global product algorithm. First, global products are not optimized for any particular region, but are generalized for a wide range of conditions. Second, these algorithms were designed to map forest conversion and forest cover without additional data sources, such as the forest/nonforest mask applied in this study. VCC data had very low commission errors, accurately identifying very large clearings but missing a substantial percentage of clearings of all sizes. Although the MOD44B percent of tree-cover data were created at 500-m resolution, VCF data performed comparably to other techniques. This performance suggests that a 250-m VCF product could be highly accurate for annual deforestation monitoring. In addition, a VCF percent of the tree-cover product could be used as an initial cloud-free forest mask in the Brazilian Amazon or in other deforestationmonitoring efforts. Using the VCF product as a forest/nonforest mask would enable the extension of the simple methods presented in this study in other regions.

Deforestation detection accuracy was especially sensitive to the degree of forest fragmentation in each test scene. In highly fragmented forest conditions such as scene 223/66, VCF, soil fraction, and EVI inputs constructed from 500-m data generated a high number of edge-effect commission errors. In scenes with more continuous forest cover, edge-effect errors as a result of 500-m source data or 250-m MODIS resolution more generally were less problematic. With only two MODIS bands at 250-m resolution, future subpixel spectral unmixing at 250-m resolution may need to focus on red and NIR unmixing algorithms that have been applied to data from other sensors (Hall et al. 1995).

Results reflect the accuracy of automated techniques without the additional human interpretation. Common errors were false detections along river courses and at the forest/nonforest boundary, even after removing an edge pixel from the forest mask. Mixed pixel effects, changing water levels, and varying nominal spatial resolution (depending on view angle) could account for many of these false 
detections. In some cases, trained interpreters could easily recognize and remove these detections. In addition, the removal of small clusters (one and two pixels) could also reduce errors.

We tested simple change detection methods with low computer processing and data storage requirements. Many methods performed well in the test scene analysis. The most appropriate method for monitoring deforestation in the Brazilian Amazon will depend on the need to balance omission and commission errors with the detection of new clearings of various sizes. Additional components that influence the choice of input data and the detection method are the frequency of monitoring efforts and the need to perform under cloudy conditions.

\subsection{Field validation}

Field validation of MODIS classification results in central Mato Grosso generated two important measures of classification accuracy. The method proved highly accurate for identifying deforestation events, with 100\% accuracy for observed clusters larger than two pixels. Detection accuracy was lower on a per-pixel basis because of subpixel deforestation edge effects. All pixels that were classified as forest, but were observed to contain some new deforestation, were located at the forest/deforestation edge. Future analyses will focus on the subpixel fraction of deforestation within these edge pixels.

Study design for field validation made omission errors difficult to quantify. Pixel- and cluster-based approaches were stratified by accessibility with a vector layer of Mato Grosso roads. All pixels and clusters that intersected a road were considered part of the validation sample. Field observers were directed to forest and deforested samples based on classification results, not to likely areas for omission. As a result, characterization of omission was only possible through anecdotal evidence from chance observations. Future validation campaigns should more accurately quantify omission errors.

Field validation was made possible through quality equipment and highly accessible terrain. The combination of near-coincident Landsat TM and MODIS data with real-time GPS proved excellent for evaluating MODIS pixels and clusters in the field. The unpaved road network in central Mato Grosso is extensive, which facilitated access to a variety of sampling conditions. Ground-based field validation without high-resolution imagery or roaded access would yield significantly fewer sample observations.

\subsection{Mato Grosso deforestation 2001-04}

Analysis of the deforestation in Mato Grosso between 2001 and 2004 showed an increase in the total number of MODIS deforestation clusters over the 3-yr period and a substantial difference in the number of large clusters in 2001-02 versus 2002-03 and 2003-04. Because MODIS-based estimates of the deforestation area did not correlate well with the total deforestation area from PRODES in test scene analyses, trends in MODIS deforestation detections cannot be directly translated into trends in the deforestation area. However, large clearings do account for a substantial portion of the total deforestation increment each year in Mato Grosso (Fearnside and Barbosa 2003). Therefore, an increase in MODIS deforestation 
Earth Interactions - Volume 9 (2005) - Paper No. 8 • Page 20

detections of large clusters suggests an increasing deforestation area that should be confirmed with high-resolution mapping in Mato Grosso for this period.

Initial deforestation estimates for Mato Grosso from PRODES for 2002 and 2003 support the MODIS-based result. For the Legal Amazon, $2002\left(23260 \mathrm{~km}^{2}\right)$ and initial $2003\left(23750 \mathrm{~km}^{2} \pm 4 \%\right)$ deforestation estimates from PRODES are similar (information online at http://www.obt.inpe.br/prodes/). However, PRODES estimates of deforestation in Mato Grosso for 2001-02 $\left(7478 \mathrm{~km}^{2}\right)$ and 2002-03 (10 $416 \mathrm{~km}^{2}$ ) show a 40\% increase in deforestation (as above, see online at http://www.obt.inpe.br/prodes/). This increase in deforested area supports the MODIS-based findings of more large deforestation clusters in 2002-03 than in 2001-02. Additional high-resolution efforts for the entire state are required to confirm these findings and to investigate similar results for deforestation in 200304. Obtaining an accurate estimate of deforestation area is particularly important because previous research showed a slowing of deforestation rates between 1999 and 2002 that may have reversed in recent years (Fearnside and Barbosa 2003; Fearnside 2003).

\section{Conclusions}

MODIS 250-m resolution data can be used to accurately identify the location of new deforestation with simple change detection algorithms and minimal data processing and storage needs. A forest/nonforest mask is an essential component of the MODIS-based deforestation-detection methods in this study. Application of these results outside the Brazilian Amazon may be possible through the use of the VCF percent of tree-cover data as a forest mask.

The results from this study also highlight the trade-offs between the detection of deforestation area, small and large polygons, and minimizing commission errors. MODIS-based methods presented in this study identified high percentages of available polygons larger than 3 ha with low commission, but did not detect consistently high percentages of PRODES deforestation area. As a result, the methods presented in this study are not a substitute for high-resolution analysis to estimate deforestation area and the number of small clearings.

A monitoring system that combines frequent deforestation monitoring with MODIS and annual high-resolution mapping efforts could benefit from shared input and output datasets. For example, MODIS-based results on the location and trends in deforestation could help to prioritize high-resolution analyses. Annual high-resolution analyses would then provide detailed estimates of deforestation area and small clearings, creating an updated forest mask for use with subsequent MODIS monitoring efforts.

Acknowledgments. This study was funded by NASA Grant NCC5693 as part of the Large-Scale Biosphere-Atmosphere Project in the Amazon (LBA-ECO). The authors thank three anonymous reviewers for helpful comments on an earlier version of this manuscript, colleagues at the University of Maryland, College Park, and Instituto Nacional de Pesquisas Espaciais in São José dos Campos, Sao Paolo, Brazil, for support during data analysis and field validation components of this research, and the NASA and Instituto Nacional de Pesquisas da Amazônia coordinators of the Large-Scale BiosphereAtmosphere Project in the Amazon for their continued collaboration. Data for this study 
Earth Interactions • Volume 9 (2005) • Paper No. 8 • Page 21

were provided by the Land Processes Distributed Active Archive Center (LP-DAAC; information available online at http://edcdaac.usgs.gov) and Instituto Nacional de Pesquisas Espaciais (INPE; information online at http://www.obt.inpe.br/prodes/).

\section{References}

Anderson, L., Y. Shimabukuro, R. DeFries, and D. Morton, 2005a: Assessment of land cover changes in the Brazilian Amazon using multitemporal fraction images derived from Terra MODIS: Examples from the state of Mato Grosso. IEEE Trans. Geosci. Remote Sens., in press.

,-- , and E. Arai, 2005b: Multitemporal fraction images derived from Terra MODIS data for analysing land cover change over the Amazon region. Int. J. Remote Sens., in press.

Asner, G. P., 2001: Cloud cover in Landsat observations of the Brazilian Amazon. Int. J. Remote Sens., 22, 3855-3862.

Braswell, B. H., S. C. Hangen, S. E. Frolking, and W. A. Salas, 2003: A multivariable approach for mapping sub-pixel land cover distributions using MISR and MODS: Application in the Brazilian Amazon region. Remote Sens. Environ., 87, 243-256.

Carroll, M., C. Dimiceli, J. R. G. Townshend, R. A. Sohlberg, and M. C. Hansen, 2004: User guide for MOD44A Vegetation Cover Conversion (VCC). University of Maryland, 6 pp. [Available online at http://glcf.umiacs.umd.edu/pdf/VCCuserguide.pdf.]

Congalton, R. G., 1991: A review of assessing the accuracy of classifications of remotely sensed data. Remote Sens. Environ., 37, 35-46.

DeFries, R., R. A. Houghton, M. Hansen, C. Field, D. L. Skole, and J. Townshend, 2002: Carbon emissions from tropical deforestation and regrowth based on satellite observations for the 1980s and 90s. Proc. Natl. Acad. Sci., 99 (22), 14 256-14 261.

Fearnside, P. M., 2003: Deforestation control in Mato Grosso: A new model for slowing the loss of Brazil's Amazon forest. Ambio, 32, 343-345.

— swering open questions. Environ. Conservation, 31, 7-10.

Hall, F. G., Y. E. Shimabukuro, and F. Huemmrich, 1995: Remote sensing of biophysical structure in boreal stands of picea mariana using mixture decomposition and geometric reflectance models. Ecol. Appl., 5, 993-1013.

Hansen, M. C., and R. S. DeFries, 2004: Detecting long term global forest change using continuous fields of tree cover maps from $8 \mathrm{~km}$ AVHRR data for the years 1982-1999. Ecosystems, doi:10.1007/s10021-004-0243-3.

,-- J. R. G. Townshend, M. Carroll, C. Dimiceli, and R. A. Sohlberg, 2003: Global percent tree cover at a spatial resolution of 500 meters: First results of the MODIS Vegetation Continuous Fields algorithm. Earth Interactions, 7. [Available online at http:// EarthInteractions.org.]

Hess, L. L., and Coauthors, 2002: Geocoded digital videography for validation of land cover mapping in the Amazon basin. Int. J. Remote Sens., 23, 1527-1556.

Houghton, R. A., D. L. Skole, C. A. Nobre, J. L. Hackler, K. T. Lawrence, and W. H. Chomentowski, 2000: Annual fluxes of carbon from deforestation and regrowth in the Brazilian Amazon. Nature, 403, 301-304.

Huete, A. R., C. Justice, and W. Van Leeuwen, 1999: MODIS vegetation index (MOD13). Algorithm Theoretical Basis Document (ATBD), 122 pp. [Available online at http://modis. gsfc.nasa.gov/data/atbd/atbd_mod13.pdf.]

Justice, C. O., J. R. G. Townshend, E. F. Vermote, E. Masouka, R. E. Wolfe, S. Saleous, D. P. Roy, and J. T. Morisette, 2002: An overview of MODIS Land data processing and product status. Remote Sens. Environ., 83, 3-15. 
Laurence, W. H., A. K. M. Albernaz, P. M. Fearnside, H. L. Vasconcelos, and L. V. Ferreira, 2004: Deforestation in Amazonia. Science, 304, 1109.

Malingreau, J. P., F. Achard, G. D'Souza, H. J. Stibig, J. D'Souza, C. Estreguil, and H. Eva, 1995: AVHRR for global tropical forest monitoring: The lessons of the TREES project. Remote Sens. Rev., 12, 29-40.

Nelson, R., and B. Holben, 1986: Identifying deforestation in Brazil using multiresolution satellite data. Int. J. Remote Sens., 7, 429-448.

— N. Norning, and T. A. Stone, 1987: Determining the rate of forest conversion in Mato Grosso, Brazil, using Landsat and AVHRR data. Int. J. Remote Sens., 8, 1767-1784.

Roberts, D. A., I. Numata, K. W. Holmes, G. Batista, T. Krug, A. Monteiro, B. Powell, and O. Chadwick, 2002: Large area mapping of landcover change in Rondônia using multitemporal spectral mixture analysis and decision tree classifiers. J. Geophys. Res., 107, 8073, doi:10.1029/2001JD000374.

Sader, S. A., D. J. Hayes, J. A. Hepinstall, M. Coan, and C. Soza, 2001: Forest change monitoring of a remote biosphere reserve. Int. J. Remote Sens., 22, 1937-1950.

Salati, E., and C. A. Nobre, 1991: Possible climatic impacts of tropical deforestation. Climate Change, 19, 177-196.

Shimabukuro, Y. E., and J. A. Smith, 1995: Fraction images derived from Landsat Thematic Mapper images of the Amazon Region. Can. J. Remote Sens., 21, 67-74.

— B. B. Holben, and C. J. Tucker, 1994: Fraction images from NOAA AVHRR for studying the deforestation in the Brazilian Amazon. Int. J. Remote Sens., 15, 517-520.

— , V. Duarte, E. M. K. Mello, and J. C. Moreira, 1999: RGB shade fraction images derived from multitemporal Landsat TM data for studying deforestation in Brazilian Amazon. Int. J. Remote Sens., 20, 643-646.

Siqueira, P., B. Chapman, and G. McGarragh, 2003: The coregistration, calibration, and interpretation of multiseason JERS-1 SAR data over South America. Remote Sens. Environ., 87, 389-403.

Skole, D. L., and C. Tucker, 1993: Tropical deforestation and habitat fragmentation in the Amazon: Satellite data from 1978-1988. Science, 260, 1905-1910.

Stibig, H.-J., J. P. Malingreau, and R. Beuchle, 2001: New possibilities of regional assessment of tropical forest cover in insular Southeast Asia using SPOT-VEGETATION satellite image mosaics COVER. Int. J. Remote Sens., 22, 503-505.

Venables, W. N., and B. D. Ripley, 1994: Modern Applied Statistics with S-Plus. Springer-Verlag, $512 \mathrm{pp}$.

Werth, D., and R. Avissar, 2002: The local and global effects of Amazon deforestation. J. Geophys. Res., 107, 8087, doi:10.1029/2001JD000717.

Wessels, K. J., R. S. DeFries, J. Dempewolf, L. O. Anderson, A. J. Hansen, S. L. Powell, and E. F. Moran, 2004: Mapping regional land cover with MODIS data for biological conservation: Examples from the Greater Yellowstone Ecosystem, USA, and Pará State, Brazil. Remote Sens. Environ., 92, 67-83.

Zhan, X., R. Sohlberg, J. R. G. Townshend, C. DiMiceli, M. Carroll, J. C. Eastman, M. C. Hansen, and R. S. DeFries, 2002: Detection of land cover changes using MODIS $250 \mathrm{~m}$ data. Remote Sens. Environ., 83, 336-350.

Earth Interactions is published jointly by the American Meteorological Society, the American Geophysical Union, and the Association of American Geographers. Permission to use figures, tables, and brief excerpts from this journal in scientific and educational works is hereby granted provided that the source is acknowledged. Any use of material in this journal that is determined to be "fair use" under Section 107 or that satisfies the conditions specified in Section 108 of the U.S. Copyright Law (17 USC, as revised by P.IL. 94-553) does not require the publishers' permission. For permission for any other form of copying, contact one of the copublishing societies. 
Copyright of Earth Interactions is the property of American Meteorological Society. The copyright in an individual article may be maintained by the author in certain cases. Content may not be copied or emailed to multiple sites or posted to a listserv without the copyright holder's express written permission. However, users may print, download, or email articles for individual use. 